\title{
Postmodernism and customer centricity
}

\author{
Amirreza Mehraramolan \\ DBA (Doctorate in Business Administration) Student at University of Bradford, School of Management, \\ Bradford, UK \\ Email address of the Author: rainman82@gmail.com, amehrara@student.bradford.ac.uk \\ Tel: 00447596861438 \\ Postal address: 53 Parkes Building, The Poplars, Beeston, Nottingham, NG9 2UY
}

Received: 31 January 2015 / Revised: 5 March 2016 / Accepted: 8 March 2015 / Published online: 6 May 2016

\begin{abstract}
There are many different explanations of customer centricity, and many people are in support of that concept whereas many others are against it. Different meanings can be found for customer centricity in literature. Which one could be the proper and most reliable one? Most of the views on customer centricity are based on foundational philosophical approaches and many different patterns are set as a guideline for the organizations which are willing to be customer-centric. In this paper, the aim is to look at the customer centricity phenomenon from the postmodernist point of view. The question of this study is linked to an anti-foundational philosophical approach (postmodernism) and it is shown how different the answers could be based on the philosophy approach that we choose. To collect the data, 10 in-depth interviews were done with senior business managers of customer-centric organizations in Iran. The results showed completely different answers from the postmodernist point of view.
\end{abstract}

JEL classification: M10, L10

Keywords: postmodernism, positivism, customer centricity, phenomenology.

\section{INTRODUCTION}

Today, most of the companies claim that they are customer-centric but actually they are not. If we check the structures and processes of these companies, we will find them so far away from being customer-centric. Many people believe that customer centricity is just a myth and it is something just for the books and journals while in the real world of business the practices of customer centricity are not implemented by companies because they seem to be against profitability. The proposed question of the paper is as follows: What is a customer-centric organization? In this paper, it has been decided to analyse the above research question from the postmodernist point of view. First, an explanation of the epistemology is mentioned and then the research question is analysed using epistemology, and finally a conclusion of the discussion of customer centricity from the postmodernist perspective is outlined. 


\section{LITERATURE REVIEW}

Traditionally, in order to make a link between philosophical approaches and management topics, most business and management schools tend to develop their curricula based on positivism rather than postmodernism and most of the major theories and patterns taught in business schools are based on the positivist assumptions. Positivism does not have any works dealing with values, feelings, emotions or spiritual things and its base is just numbers, statistics and figures. It sees the truth in this way and positivists do not believe that the truth can be subjective (the point that postmodernists believe) (Stark et al., 2008).

In positivism, uncertainties are reduced so the situation in this approach is more controlled. It involves more points like structures, standards and systems in comparison with postmodernism. Positivism is related to quantitative models and issues. In contrast, postmodernism represents qualitative models and concepts. Positivists try to generalize the knowledge whereas postmodernism does not follow this pattern. While making decisions, positivists try to decrease the uncertainty and ambiguity in order to reach a precise truth mostly in numbers and figures whilst postmodernism pays more attention to emotions and feelings and it does not search for evidence in numbers for establishing the reality and truth (Stark et al., 2008). In the positivist view, the world is understood in an absolute way. This should be a full understanding and there is no room for any scepticism or doubts in this approach and everything should be clear and direct. In the positivist view, all stages are predesigned and by following them, the other stages become predictable. They refer to the structures, models and general ideas you acquire, so you are able to predict the situation. Measurement is the key factor of positivism and determined measurement is applied by positivists every time and, as already mentioned, everything should be completely clear and exact for positivists (Social research method website, 2012). Positivism is based on rational thought and it believes that through rational thinking the human can make progress. The base of postmodernism, on the other hand, is questioning and rejecting things. Positivism sees the interaction between an organization and social life in an objective and rational way. In the positivist view, the organization by itself logically works with less connection with the society. Postmodernism looks more at discourses and from the postmodernist view, an organization is not completely separated from the social life and society (Cooper \& Burrell, 1988). Change and ambiguity are 2 concepts related to postmodernism. Actually, postmodernism puts us in a strange and completely different world than the other philosophical approaches. In postmodernism, nothing stays fixed and we cannot have something for a long time in order to name and recognize it. According to postmodernism, there is nothing stable and actually the world is seen from different perspectives and the truth is made based on people's thoughts. Boundaries and limitations are removed and the truth and the world are based on our thinking (Benton \& Craib, 2011).

In the postmodernist view, there is not any definite truth and the truth is made differently by different people. So it is not believed that there is only one reality and truth (Stark et al., 2008). Today, the postmodernism in business and management is against any generalizations and constant points. Actually, it cannot accept any fixed and general points and believes that every time there is an alternative view which is completely different form a general rule, so we cannot generalize. It relies on subjectivity rather than objectivity (Johnson \& Duberley, 2011). A difficult part of postmodernism is the issue that general rules and ideas and basic conceptions can be rejected and this somehow makes jobs very difficult, because it is likely to get confused or face ambiguities that cannot be handled (Berg, 1989). In postmodernism, there is no universal rule. It is not possible to reach to a verdict about something and ambiguity is the base. Another important point of postmodernism is the issue that the world is seen differently, each person has a different interpretation of the world, there is no single explanation of the world and there are many different ideas around the world. Postmodernism is based on variety rather than similarity (Williams \& May, 1996). Postmodernism questions the truth and reality. From the postmodernist 
point of view, there is no way to define some structures and pattern for reality. No truth or reality is found in postmodernism because its base is scepticism. In fact, definite values or realities that are believed by a majority of people are questioned by postmodernism. Actually, it rejects any kind of truth. Spiritual and moral issues related to people are given more attention in postmodernism and issues like social activities and interactions among them are the key points that are covered by postmodernism. The world uncertainty is a symbol of postmodernism. In fact, postmodernists believe we live in an uncertain time and we should be ready for new changes. They believe that a precise definition or explanation of a dream future for all the people is not possible and we cannot specify a dream pattern that will apply to everybody in the future. They consider variety as something valuable and believe in change and variety rather than any fixed or constant thing. Postmodernism pays more attention to individuals and focuses on the perceptions, opinions and values of individuals more because it believes that different people understand the world differently, so we should listen to different opinions of different ones in order to get more details (Kilduf \& Mehra, 1997).

In postmodernism, the processes or structures of organizations do not make sense or are not the purpose as humans cannot control them in a way they like. Postmodernism claims that we should not think that the world is made just for us and that we can have its full attention and control it by ourselves or that we are in the centre of control. There is no logical definition of the world and only some interpretations can be made about it. Therefore, there is no fixed rule about the world. One of the criticisms against postmodernism is that we do not have any certain knowledge; there is not any foundation or any certain base so sometimes this uncertainty can be confusing and difficult. Postmodernism cannot accept any reason or truth. In postmodernism, there is no predesigned pattern or presumption (Cooper \& Burell, 1988). Galbraith (2005) remarked on the star model of companies and he mentioned that each company is surrounded with 5 different dimensions. The strategy dimension is at the top of this model and the other 4 dimensions including people, rewards, processes and structures should be in complete accordance with the strategy. When a company wants to be customer-centric, actual changes should be applied to all these five dimensions. So just paying more attention to the customers does not mean that the company is customer-centric (Galbraith, 2005).

Figure 1

The star model (Galbraith, 2005)

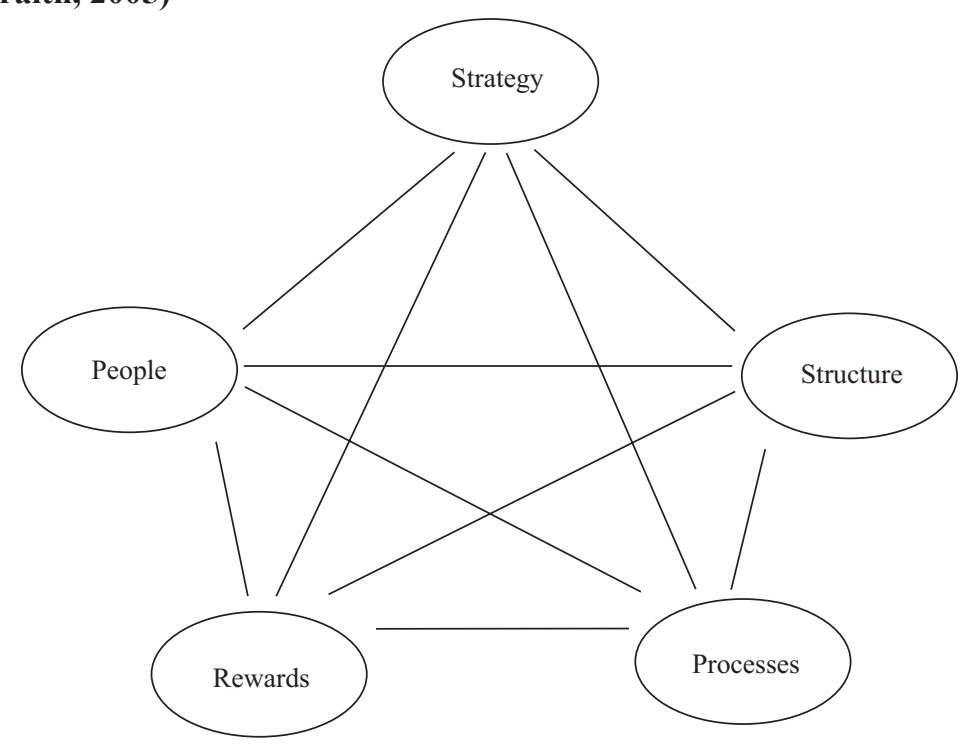

Referring to the strategy dimension, in a product-centric organization the most important goal is to offer the best product to the customer. According to the structure dimension, it is important 
for them to consider customer segments and specific customer teams in their company charts. Referring to the process dimension, in a customer-centric company the most important thought is about finding a new solution for the customers. According to the rewards and people dimensions, in a customer-centric company the reward system is based on customer opinions and the people who are in the relationship segment with the customers are the strongest people in the company (Galbraith, 2005). Actually, the definition mentioned by Galbraith is exactly a definite explanation of customer centricity from the positivist point of view that believes that an organization, to be customer-centric, needs to follow certain rules.

On the other hand, postmodernism believes that when a general rule or a very concentrated topic is mentioned in an organization, many other factors will be eliminated and forgotten. For instance, when in an organization all dimensions including strategies, processes and structures are set based on the customer-centric approach and the customer is on the main radar of the company, everything revolves around customers and many other opportunities or factors would be skipped because all attention and focus is just around the customers. That is why postmodernism questions the identity of the customer centricity approach and asks why it should be adopted by organizations and why organizations think that they need to be customer-centric in order to be more successful. Postmodernism asks why companies do feel that they have to have a customer-centric culture in their organizations and why the customer centricity expression has been getting so popular in these days. Today, many companies are very successful so why do we feel that we need to be customercentric in order to be a successful company? Consequently, when it comes to the postmodernist view, all the questions mentioned above can be considered as sub-questions the answers to which can be related to the main question of this research, revealing a new side of customer centricity.

Many people with postmodern views believe that giving too much attention to customers and sacrificing everything for their sake can be counterproductive and the experiences show that providing too much service to customers is not a guarantee of their loyalty. However, the experiences have shown that customers react to bad services very soon and punish the companies that are bad at providing them. So they punish bad service very quickly but do not reward very good service very quickly, which means that companies keeping their services in a moderate range rather than providing too bad or too good service are more logical. They should not be absolutely customer-centric and the structures, processes and strategies should not be set entirely based on the customers' needs and opinions. Other important factors except the customers should be paid attention to as well. (Dixon et al., 2010).

Dixon (et al., 2010) undertook a study to find the link between loyalty and customer service. There were around $75000 \mathrm{~B} 2 \mathrm{~B}$ and B2C customers in that research and finally the result showed that delighting the customers did not lead to loyalty and companies should not think that they could be very successful just through customer centricity. At the moment, we have many companies that are not customer-centric but they are very successful. Unfortunately, many companies accept very high costs of transforming themselves into customer-centric ones and they pay this major cost with a dream of improving and reaching the top in the market but the result becomes inverse and they cannot get the result they have expected. So, literally, is just wasting their financial resources without getting whatever they have dreamed of (Dixon et al., 2010)

\section{METHODOLOGY}

Under the postmodernist approach, 10 in-depth unstructured interviews were done with senior managers in Iran whose companies are very successful in the Iranian market and whose approaches were different from the traditional approach of customer centricity. Each interview took about 30 minutes and during the interview the ultimate effort was made to gather as many details and as much information from the interviewees as possible. 
For analysing the interviews, the phenomenological approach was used. "The aim of phenomenological data analysis is to transform lived experience into a textual expression of its essence - in such a way that the effect of the text is at once a reflexive re-living and a reflective appropriation of something meaningful" (Van Manen,1997, p. 36).

The attempt is to analyse the main research question: "What is a customer-centric organization?" The question is analysed based on the postmodernist approach. When we look at the postmodernist approach from this point of view, we come across some other sub-questions as follows:

Why do organizations think that in order to be more successful, they need to be customercentric and is a customer-centric capability necessary in the real world?

Why do companies feel that they have to have customer-centric culture in their organizations?

By means of phenomenology, it was tried to define the themes and we can consider the themes gained through phenomenology as the structure of experience. This analysis methodology is used in research related to the interpretivism approach rather than positivism (Van Manen, 1997).

Postmodernism believes that the knowledge is built based on the experiences that a person gains throughout his/her life. So the best analysis methodology for the postmodernist view of customer centricity can be phenomenology. The process of the analysis through phenomenology was as follows. First, the written transcripts were reviewed many times to understand them generally. In each transcript, significant sentences were highlighted and then their key meanings were extracted. Subsequently, those were grouped under themes in order to get the precise understanding of the concept. As a next step, a relationship was established between the literature and themes of the interview and at last, the themes were reviewed critically and a final report was made on the research findings.

In terms of data management, one code was allocated to each participant. The participants were coded as P 1, P 2, ..., P 10. This type of coding allowed me to distinguish the transcripts of participants very easily. The research participants' characteristics including their age, gender, job position and their economic sector are mentioned in Table 1.

Table 1

\begin{tabular}{|c|c|c|c|c|}
\hline Codes & Age & Gender & Job position & Economic sector \\
\hline P 1 & 42 & Male & Managing Director & Dentistry \\
\hline P 2 & 57 & Male & Customer Relationship Manager & Banking \\
\hline P 3 & 36 & Female & Sales Manager & Tourism \\
\hline P 4 & 40 & Male & Account Manager & Pharmaceutical \\
\hline P 5 & 47 & Male & Managing Director & Education \\
\hline P 6 & 34 & Female & Head of Marketing & Dentistry \\
\hline P 7 & 49 & Male & Branch Manager & Banking \\
\hline P 8 & 52 & Female & Export Manager & Agriculture \\
\hline P 9 & 55 & Male & Customer Relationship Manager & Banking \\
\hline P 10 & 41 & Male & Managing Director & Education \\
\hline
\end{tabular}

\section{RESULTS}

Finally, three themes were gained from the interviews with senior managers that were connected to the main research question and the other sub-questions through the postmodernist approach. 
- Theme 1: customized production is one of the main aspects of the customer-centric organization and many companies have become customer-centric due to reaching this point.

They believe that customization is a vital point of current business around the world and customers in these days like to have customized products instead of any mass production. It means flexibility and being able to adapt to change. As P 2 mentions:

Some customers prefer to use our on-line internet banking and some of the other prefer to get service physically in our branches and some other use our telephone banking and they are asking us to provide the service based on their personal preferences and all these points are a clear sign for us to understand that customers like to receive a customized product and service based on their personal preferences.

Another manager (P 8) who works in the agriculture sector stated:

We have different customers who have different preferences and if we want to be a customer-centric one we have to keep all of them satisfied and it means we have to be ready to change our services and products based on their needs and this customization is something that can bring us a very good competitive advantage in comparison to our competitors.

The postmodernist approach includes customization and change and from the postmodernist perspective, this customization can be considered as the main aim that leads to companies becoming customer-centric. Other managers (P 3, P 5, P 10) also emphasized the importance of customization for a customer-centric company.

- Theme 2: Respect plays a pivotal role in attracting the customers' attention and this is their preference. This is what makes them ready to make a long-term commitment and keeps them loyal.

The respondents believe that if the customers notice that they are on the main radar of the company and the company attempts to adapt to the customers' needs, customers will definitely think of themselves as an inseparable part of that company and they will look at it as their closeknit family. They will appreciate the company's desperate effort and see that it is doing its best to retain their customers and change its structures and strategies in line with their desires. Therefore, these attempts would give the customers credit and they would feel important. In fact, they usually want to be treated as individuals rather than to be seen as a business target. So in this way, the company would show its great appreciation to its customers for being so faithful and on the other hand, the customers would keep this company as their first choice of shopping. As a result, every individual would live in peace. One of the managers (P 4) mentions:

Every month I meet various different customers and they behave differently but towards all of them I have to be respectful because I know if I lose my temper or I am not respectful enough towards them, it can destroy the image of our company and they will prefer not to work with us even though our products are of a higher quality than the others.

All in all, customer-centric companies do not think about anything just in business and profit terms and they believe that customer centricity is valuable for society as well. This is because people are more satisfied when their preferences are paid attention to and when they are treated without any negative feeling of being haunted by the companies, which results in a society of happier people who interact with each other with more respect. In a world where changes are happening so fast and technologies are adverting to the people's life, it is assumed that some moral issues are faded away and rarely can we find the ethical issues in the current business around the world. But by considering the customer-centric approach, new methods of interaction between the customers and companies can probably be developed.

- Theme 3: complex and negotiated relationships also tempt companies to adopt a customercentric culture in their organizations. 
The postmodernist view on customer centricity puts emphasis on the point that the atmosphere and culture of open communication and relationships within an organization can be very useful and helpful for customer-centric companies. This point is exactly against any constant rules or structures or any standards. In line with this idea, one of the mangers (P 10) believes as below:

The customer-centric companies can show their best performance when they have an open communication inside themselves and there should be a quick communication channel available for all employees at different levels of the organization. This kind of open relationships inside an organization makes the company powerful and capable of undertaking customer centricity activities.

The respondents believe that a customer-centric organization should have negotiated relationships inside instead of conforming to rules or rigid standards. Generally, those approaches that postmodernists use to analyse customer centricity are based on subjectivity and interpretations. Normally, under the postmodernist approach, a customer-centric organization has fewer limitations and standards than in the positivist view. The definitions of a customer-centric organization are completely different for a positivist and a postmodernist because the bases of these 2 approaches are really different.

\section{CONCLUSION}

The results showed that customer centricity is viewed completely differently by postmodernists. They question customer centricity and seek to find out about the reason why companies should become customer-centric or about the effects that customer centricity can have on society. They are more concerned about detailed reasons for customer centricity rather than any other factors like proper structures, processes or strategies. Based on the analysis of the interviews, it was found that customer centricity involves arousing a good feeling of respect for customers and this makes them happier. In this way, we can have a better society as well as more satisfied customers because they would feel that they are part of the company, not just a target, so they would feel more involved with companies and show more commitment to them. Also, customized production and negotiable relationships inside an organization are other factors that, from the postmodernist point of view, are the main reasons for companies to be customer-centric.

Customized production, improvised strategies, complex and negotiated relationships, democratic processes and strategies, diversity, creativity and selection are the main features of the postmodernist approach and finding these key features in customer centric organizations is more important for postmodernists than finding a proper structure or process for becoming customer-centric. Actually, positivism is a deductive approach and moves from general ideas to specific details in order to draw a conclusion. Postmodernism does not work like this: it is based on interpretation and does not necessarily look for a definite conclusion or result. It believes that organizations probably become customer-centric because of customization or respect they have for their customers and they can operate in any structure or have any strategies. In contrary, positivism argues that if a company wants to be customer-centric, it should be involved in certain structures and follow some strategies. Such is the correct way and there is no other possibility for them to be customer-centric whereas the exact way or absolute truth for customer centricity does not make any sense for postmodernists. Actually, positivism limits customer-centric organizations in some ways whilst postmodernism is against definite rules or absolute truth. Therefore, postmodernism focuses more on discourses of customer centricity and its own interaction with the society and does not think about any structured rules. Besides, the postmodernist approach questions the extreme customer centricity and believes that customer centricity should be achieved in a logical way. Companies should not think that by following the customer centricity path, they can reach all of their dream goals and their expectations should be logical. Customer centricity should not 
let companies forget about other important factors and they should not sacrifice everything just in order to be customer-centric. We should consider that it is likely to see different opinions about postmodernism and positivism among managers in other countries with different cultures and also different political and economic situations. These philosophical approaches, and especially postmodernism, are so much reliant on culture and situation, and managers in Iran, which is an emerging country and expects to see more international business in coming years, think more about intangible aspects like respect or relationship rather than physical elements that were dominant in the Iranian market for many years. In developed countries, managers are more concerned about co-creation of value in customer centric organizations and considering this new concept and connecting it to philosophical approaches can be a very good topic for any future research.

\section{References}

Agnew, N.M. and Pyke, W. (1987) The science game: an introduction to research in the social science, $4^{\text {th }}$ edition, London: Prentice Hall.

Benton, T. and Craib, I. (2011) Philosophy of social science, New York: Palgrave Macmillan.

Berg, L. (1989) Qualitative research methods for the social science, Boston: Allyn and Bacon.

Burmann, C., Meurer, J. and Kanitz, C. (2011) "Customer Centricity as a Key to Success for Pharma”, Journal of Medical Marketing: Device, Diagnostic and pharmaceutical marketing, 11(1), pp. 49-59.

Clegg, S.R. and Kornberger, M. (2003) "Modernism, Postmodernism, Management and Organization Theory", Research in the sociology of organizations, 21, pp. 57-88.

Cooper, R. and Burrell, G. (1988) "Modernism, postmodernism and organizational analysis: an introduction", Organizational studies, 9(1), pp. 91-112.

Delanty, G. and Strydom, P. (2010) Philosophies of social science the classic and contemporary readings, London: Open University Press, McGraw Hill Education.

Dixon, M., Freeman, K. and Toman, N. (2010) "Stop trying to delight your customers", Harward Business Review, July-August, pp. 116-122.

Galbraith, J. R. (2005) Designing the customer - centric organization: a guide to strategy, structure, and process, San Francisco: Jossey- Bass.

Indick, W. (2002) "Fight the power: the limits of empiricism and the costs of positivism rigor", Journal of psychology, $136(1)$, p. 21.

Johnson, P. and Duberley, J. (2011) Understanding management research, London, Sage.

Kilduff, M. and Mehra, A. (1997) "Postmodernism and Organizational research", Academy of Management Review, 22(2), pp. 453-481.

Stark, E., Stepanovich, P., Poppler, P. And Hopkins, P.J. (2008) "Surrounded by White Water: Conflicts in Management Sciences Regarding Truth and Reality”, Journal of Behavioral \& Applied Management, 9(3), pp. $258-274$.

Taylor, B.C. (2005) "Postmodern theory", in: May, S. and Mumby, D. (Eds.), Engaging organizational communication theory and research, Thousand Oaks, CA: Sage.

Trochim, W.M.K. (2006) Web centre for Social Research Methods. Retrieved 20/12/2012 from http//www. socialresearchmethods.net/.

Van Manen, M. (1997) Researching lived experience: human science for an action sensitive pedagogy, $2^{\text {nd }}$ edition, London: The Althouse Press.

Williams, M. and May, T. (1996) Introduction to the philosophy of social research, London: Routledge. 